\title{
Voltage collapse point evaluation considering the load dependence in a power system stability problem
}

\author{
Zaid García Sanchez ${ }^{1}$, Jose Antonio Gonzalez Cueto $\mathrm{Cruz}^{2}$, Gustavo Crespo Sanchez ${ }^{3}$, \\ Hernán Hernández Herrera ${ }^{4}$, Jorge Ivan Silva Ortega ${ }^{5}$ \\ ${ }^{1,2,3}$ Center of Energy and Environmental Studies Department, Universidad de Cienfuegos, Cuba \\ ${ }^{4}$ Facultad de Ingenierias, Universidad Simón Bolivar, Colombia \\ ${ }^{5}$ Energy Department, Universidad de la Costa, Colombia
}

\begin{abstract}
Article Info
Article history:

Received Jan 14, 2019

Revised Aug 17, 2019

Accepted Aug 29, 2019

\section{Keywords:}

Maximum point of load

Modal analysis

Voltage collapse

Voltage stability

ABSTRACT

Voltage Stability has emerged in recent decades as one of the most common phenomena, occurrence in Electrical Power Systems. Prior researches focused on the development of algorithm indices to solve the stability problem and in the determination of factors with most influence in voltage collapse to solve the stability problem. This paper evaluates the influence that the load dependence has with the voltage on the phenomenon of the voltage stability and especially on the characteristics the collapse point or instability point. Load modeling used is detailed and comparisons of the results obtained are made with those described in the bibliography and those obtained with commercial software. The results of the load margin are also compared when a constant load or a voltage-dependent load is considered as well as the values obtained at the maximum load point and the point of voltage instability.
\end{abstract}

Copyright $(2020$ Institute of Advanced Engineering and Science. All rights reserved.

\section{Corresponding Author:}

Hernan Hernández Herrera, Facultad de Ingeniería, Universidad Simón Bolivar, Barranquilla, Colombia.

Email: hernan.hernandez@unisimonbolivar.edu.co

\section{INTRODUCTION}

Voltage Stability topics has been for decades a research area of interest in Electrical Power System (EPS). Contingencies scenarios showed that the phenomenon can also affect the steady state operation of all interconnected systems, for that reason they have become one of the issues most addressed in power system researches [1-6]. One of the most important topics of scientific research on voltage stability problem considers indices to predict the occurrence of voltage collapse [7-10]. These indices can be used in utilities to determine the closeness of the collapse voltage point, and is focused on establish a scalar magnitude that can be monitored when power system parameters change [11, 12]. Other aspects that have marked the development of indices to evaluate the proximity of voltage stability is the possibility of using them for real-time evaluation [13].

There is no consensus on the use of one index or another, for this selection engineers not only are focused on the precision of the index, also they use additional information that the system provides, the calculation speed and the possibility of using it to propose the necessary corrective measures to move the EPS operating point away from the voltage collapse point, which is a common task in these cases [12-14]. The index selection, then involves the necessary modeling of the EPS to obtain it, with the appropriate accuracy. Many of these indices require only the steady-state modeling of the EPS, which decreases the calculation time and this is one of the advantages over the analyzes that involve the dynamic modeling of the EPS [7]. 
One aspect to take into account in studies of voltage stability is the behavior of the load and its influence on this phenomenon [15-18]. The tools for the simulation of the stability problem consider the load to be constant, when in reality it depends on the voltage and the frequency [19]. Algorithms used in voltage stability are focused on estimate the maximum load point and to provide measures that must be taken to avoid the occurrence of voltage collapse. In this last aspect, performing the modal analysis allows the identification of critical elements and therefore provides corrective actions that must be taken to solve a voltaje stability problem. In [12] it is shown that there are different operating states if the load is considered as constant or if it is considered a voltage dependent. Therefore, the results of the modal analysis for these states are different, which means that corrective measures to avoid voltage collapse may not be adequate.

In this paper, the modeling of the required load, taking into account the changes in voltage, is detailed, showing that for the same state of operation different points of voltage collapse are reached depending on these values, focused on determinate the load margin considering voltage dependence modeling. To achieve this objective, an algorithm was developed based on power flows solutions considering load voltage dependence. This algorithm determine the maximum load point, the voltage instability point and the modal analysis to determine the most effective measures to avoid the occurrence of voltage collapse in a EPS.

\section{RESEARCH METHOD}

\subsection{A load margin}

The load margin is the most used and accepted index for the calculation of the voltage collapse, being a particular operating point in which an additional load is able to induce a voltage collapse [12]. The margins for active $(\mathrm{P})$ and reactive $(\mathrm{Q})$ power, exhibit the distance expressed in MW and MVAR respectively, from the operating point to the voltage collapse, and are calculated using the following (1):

$$
\begin{aligned}
& \lambda_{p}=P_{O P}-P_{P C} \\
& \lambda_{q}=Q_{O P}-Q_{P C}
\end{aligned}
$$

Where $\mathrm{P}_{\mathrm{OP}} \mathrm{y} \mathrm{Q}_{\mathrm{OP}}$ are the values for the operating point, $\mathrm{P}_{\mathrm{PC}}$ y $\mathrm{Q}_{\mathrm{PC}}$ are the values for voltage collapse point. $\lambda \mathrm{p}$ and $\lambda \mathrm{q}$ are the active and reactive power load margins measured in MW and MVAR respectively. In $[19,20]$ is described the voltage stability margin (VSM) considering the following (2):

$$
V S M=\frac{\left(V_{O P}-V_{P C}\right)}{\left(V_{P C}\right)}
$$

For this equation $V_{O P}$ represents the voltage at the operating point and $V_{P C}$ represents the voltage at the critical point or voltage collapse point. Figure 1 shows the previous concepts.

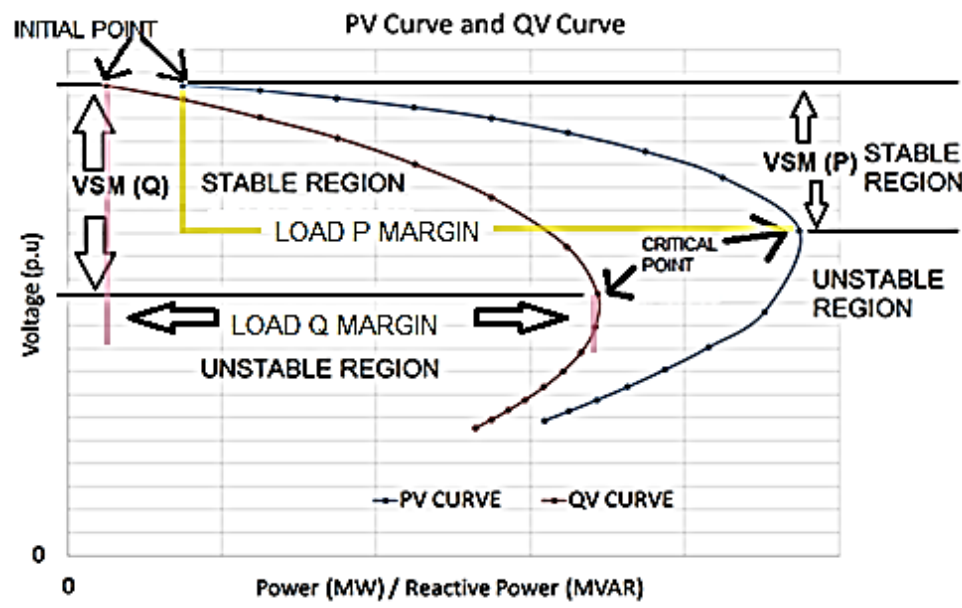

Figure 1. Load margin to voltage collapse 


\subsection{Load modeling}

Influence of load dependence on voltage

Van Cutsem (2003) describes the voltage stability as a change attempted to maintain the demand beyond the transmission and generation capacities [21, 22]. Load modeling study is then important for the steady and dynamic state associated to voltage stability. Figure 2 shows how the load can be affected in four particular operating conditions (A, B, C, D) for the voltage stability and the assembly of new operating states for the analyzed conditions and the occurrence of a voltage collapse. The difference among the points for the operating conditions becomes relevant from the planning and operation of the electrical power system perspectives.

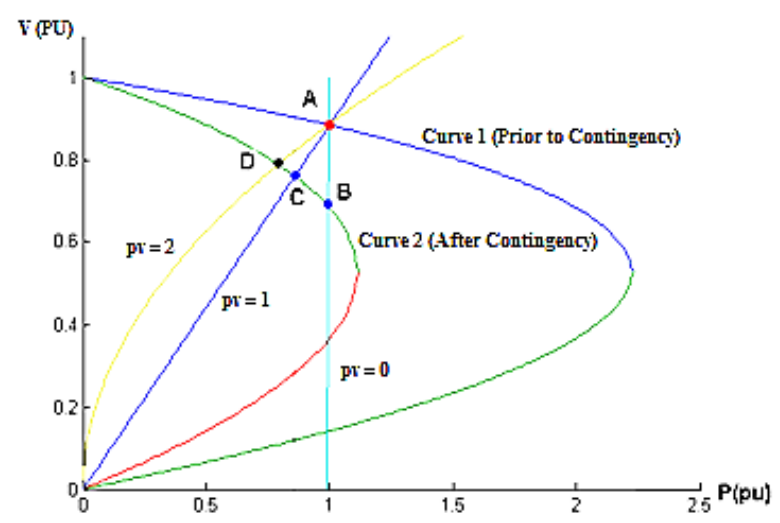

Figure 2. P-V curves for different types of load during disturbance occurrence

The base case is constructed trough the existence of a solution point (A), in which the load characteristics are intercepted next to the EPS, curve no. 1. When occurs a contingence, the constant power load intercepts the network characteristic (curve 2 at point B). nevertheless, most of the loads depend on the voltage, for example, for a load with constant current the solution is given by point $\mathrm{C}$, and for constant impedance, is given at point $\mathrm{D}$. The differences among these points are important. The situation at $\mathrm{C}$ point corresponds to conditions with less load and better values for voltage than B, where load is modeled according to the traditional model of loads flow. In this case, load impact to the system is oversized and carries out to a poor utilization of the transmission system.

Considering the variation of the load due to voltage in the methods to determine de load margins, makes the point of maximum load and the static bifurcation or instability voltage point not coincident. This problem is represented in [8] and shown in Figure 3.

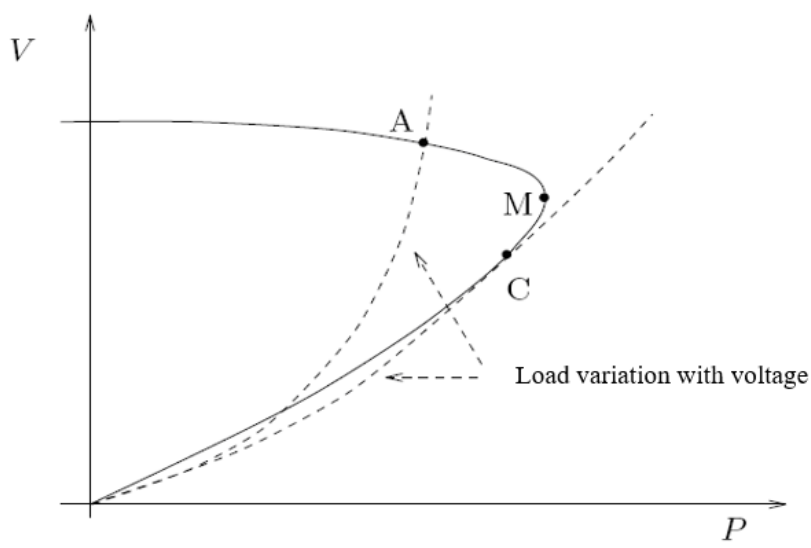

Figure 3. Curve P-V in an EPS case 
Figure 3 shows P-V curves of the case, an increase of the load makes the point moves from A to C. At point $\mathrm{M}$ the load is maximum, however, between $\mathrm{M}$ and $\mathrm{C}$ the system remains still stable. $\mathrm{C}$ corresponds to the limit of stability and $\mathrm{M}$ corresponds to the maximum load of the system, difference between both of them is due to considering a load variable to voltage [12]. A negative value for V-Q sensitivities represents an unstable operation of the system, being this, the reason why in the proposed methodology these sensitivities are calculated in order to differentiate the maximum load point and the voltage stability point.

Previous studies carried out to determine the load margin, usually are based on the obtaining the maximum load point for an EPS, however, if the dependency of the load to the voltage is considered, two different points appear, the first to the level of the load with an elevated voltage value, and the second to the level of maximum load point with a lower voltage value. The disjunction lies on which of the two points is more adequate for voltage collapse representation.

\subsection{Algorithm for load margin determination}

The algorithm developed to determine the load margin is based in the successive power flow method and when considering the variable load with the voltage, allows to determine maximum load point and/or the instability voltage point $[15,18]$, therefore, the load margin is estimated based in the maximum load point or the instability voltage point where the $\mathrm{P}_{\mathrm{PC}}$ in (1) is related with the maximum power value or the power value in the voltage instability point. To discern between these two points, it is necessary to perform a test of whether the point is stable or not and to include it as criterion of stopping the algorithm. Highligting, that the maximum load value can be identified in the $n$ iteration being greater than the $n_{-1}$ iteration. When the power decrease at any nodes in the next iteration it is shown that this node is already in the unstable region at the PV curve. The algorithm stops the calculation when at least one nodes passes to this condition. In addition, the study to be carried out is complemented with a modal analysis that allows obtaining very valuable information about the occurrence of the phenomenon, within which are the factors of participation of the generating units, the nodes and the series elements.

\subsection{Load modeling considering optimal power flow}

The studies to determine the coefficients that characterize the dependence of the load with the voltage are often complex depending on many occasions of real measurements and of the load model used [23]. The algorithm to determine the load margin used in this work considers an exponential load model described by (3).

$$
\begin{aligned}
& P=P_{0}\left(\frac{V}{V_{0}}\right)^{p v} \\
& Q=Q_{0}\left(\frac{V}{V_{0}}\right)^{q v}
\end{aligned}
$$

Where:

$P, P_{0}$ are the actual active power values of the node and active power defined at rated voltage respectively.

$V, V_{0}$ are the actual voltage and rated voltage values of the node respectively

$p v, q v$ are the coefficients that characterize the dependence with the tension of the active and reactive power respectively.

$Q, Q_{0}$ are the values of real active power of the node and active power defined at nominal voltage respectively.

In this model, the values of $P V$ and $Q V$ are used depending on the values that characterize the real load connected to the node. Different values of these coefficients make the variation of the active and reactive powers with voltage variation, thus achieving a variation of the power factor of the load. In the case that a node is composed of different load types, the resulting PV and QV values are determined by (4):

$$
\begin{aligned}
& p v_{\text {res }}=\frac{\sum_{j=1}^{n}\left(P_{j} \cdot p v_{j}\right)}{\sum_{j=1}^{n} P_{j}} \\
& q v_{\text {res }}=\frac{\sum_{j=1}^{n}\left(Q_{j} \cdot q v_{j}\right)}{\sum_{j=1}^{n} Q_{j}}
\end{aligned}
$$


In the theory of voltage instability, the maximum load point is associated with singularities of the Jacobian matrix because at the $\frac{\partial Q_{k}}{\partial V_{k}}$ point it becomes zero. This behavior influenced the development of new techniques for the analysis of voltage stability that overcome this difficulty and allow obtaining the critical point accurately and also the unstable part of the P-V curve. Although these algorithms are very accurate, they require long simulation times. Considering within the Jacobian the dependence of the load with the voltage avoids the singularity of the same in the point and allows obtaining solutions in the unstable part of the curve P-V.

The terms that characterize the dependence of the active and reactive power on the voltage are included in the Jacobian matrix terms $\frac{\partial P_{k}}{\partial V_{k}}$ y $\frac{\partial Q_{k}}{\partial V_{k}}$ of power flows respectively.

The equations $\Delta P_{k}$ and $\Delta Q_{k}$ are described as follow [23]:

$$
\begin{aligned}
& \Delta P_{k}=P_{k}^{s p}-P_{k} \\
& \Delta Q_{k}=Q_{k}^{s p}-Q_{k}
\end{aligned}
$$

Where,

$P_{k}^{s p}$ and $Q_{k}^{s p}$ are active and reactive power conected to the nodes.

$P_{k}$ and $Q_{k}$ are power flows in nodes described in [24].

The traditional Power Flow Analysis consider the load as constant, and replacing this consideration in (5) and (6) would be represented as:

$$
\Delta P_{k}=-P_{c}-P_{k} \text { and } \Delta Q_{k}=-Q_{c}-Q_{k}
$$

If the modeling of the load described by (3) is considered, it is replaced by 5 and 6 as follow:

$$
\Delta P_{k}=-P_{o}\left(\frac{V_{k}}{V_{k o}}\right)^{n p}-P_{k} \text { and } \Delta Q_{k}=-Q_{o}\left(\frac{V_{k}}{V_{k o}}\right)^{n q}-Q_{k}
$$

the Jacobian matrix terms $\frac{\partial P_{k}}{\partial V_{k}}$ y $\frac{\partial Q_{k}}{\partial V_{k}}$ are represented as:

$$
\begin{aligned}
& N_{k k}=V_{k} \frac{\partial \Delta P_{k}}{\partial V_{k}}=P_{k}+G_{k k} V_{k}^{2}+P_{c k 0}\left(\frac{V_{k}}{V_{k 0}}\right)^{(n p-1)} n p \\
& L_{k k}=V_{k} \frac{\partial \Delta Q_{k}}{\partial V_{k}}=Q_{k}-B_{k k} V_{k}^{2}+Q_{c k 0}\left(\frac{V_{k}}{V_{k 0}}\right)^{(n q-1)} n q
\end{aligned}
$$

According to the theory of voltage stability the maximum load point is associated with singularities of the Jacobian matrix because at this point the $\frac{d V_{k}}{d Q_{k}}$ becomes zero. The inclusion of the load modeling in the elements of the jacobian does not make it singular at the critical point,therefore it allows exact solutions and in the unstable region of the P-V curve.

\subsection{Stability test. Calculation of sensitivities V-Q}

As it stated above, considering the dependence of the load with the voltage cause two conceptually different points to appear in the solution: the maximum load point (M) and the voltage instability point (C) as shown in Figure 3. Due to this, the implemented algorithm must be able to discern between these two points in order that the user can determine one or the other. For this it is necessary to perform a stability test and thus determine if the EPS is at the point $\mathrm{M}$ or at point $\mathrm{C}$, this stability test is introduced as a stop criterion if what is desired is point $\mathrm{C}$.

Based on the sensitivities index detailed in [24] and [12], a negative value of the sensitivities denotes that the operation point is unstable and therefore is in the unstable zone of the PV characteristic. If any of the terms of the main diagonal of $J_{R}^{-1}$ is negative, it is because the system is at an unstable point. The load is then reduced and the stability test is carried out again, this process is repeated until a stable point is found, this point is choosen as the solution. 
The sensitivities V-Q are based on the steady state modeling of the power system and uses the traditional non-linear vector equations considered for load flow that define the variations in active and reactive power in the nodes o the system, represented as follow:

$$
\left[\begin{array}{l}
\Delta P^{p-1} \\
\Delta Q^{p-1}
\end{array}\right]=\left[\begin{array}{cc}
H^{p-1} & N^{p-1} \\
J^{p-1} & L^{p-1}
\end{array}\right]\left[\begin{array}{c}
\Delta \theta^{p} \\
\Delta V^{p} / V^{p-1}
\end{array}\right]
$$

The linearized (11) can be expressed as:

$$
\left[\begin{array}{c}
\Delta P \\
\Delta Q
\end{array}\right]=\left[\begin{array}{c}
J_{P \theta} J_{P V} \\
J_{Q \theta} J_{Q V}
\end{array}\right]\left[\begin{array}{l}
\Delta \theta \\
\Delta V
\end{array}\right]
$$

Where

$\triangle P$, Incremental change of active power in the nodes.

$\Delta Q$, Incremental change of reactive power in the nodes.

$\Delta \theta$, Incremental change of voltage angle in the nodes.

$\Delta V$, Incremental change of voltage magnitude in the nodes.

The voltage stability is affected by active and reactive power. However, at each point of operation, the active power is kept constant and the voltage stability is evaluated considering the incremental relation between voltage and reactive power. This is an analogy to the $\mathrm{Q}-\mathrm{V}$ curve technique. Since incremental changes in active power $(\Delta \mathrm{P})$ are neglected in the formulation, the loads variations in power is taken into account studying the incremental ratio of reactive power and voltage in different operating states.

Based on the above considerations, it is said $\Delta P=0$ and (12) can be expressed as:

$$
\Delta Q=J_{R} \Delta V
$$

Where,

$$
J_{R}=\left\lfloor J_{Q V}-J_{Q \theta} J_{P \theta}^{-1} J_{P V}\right\rfloor
$$

$J_{R}$ is the reduced Jacobian matrix of the system and (14) can be written as:

$$
\Delta V=J_{R}^{-1} \Delta Q
$$

The diagonal elements $i^{\text {th }}$ are the sensitivities V-Q at the node $\mathrm{i}$, these represent the slope of the Q-V curve at each point of operation [20]. A positive value of the sensitivities indicates that the system is stable and a negative value indicates that they system is in an instable operation area, becoming infinite at the limit point.

\section{RESULTS AND ANALYSIS}

The algorithm developed has been implemented in the software PSX. The study case analyzed is the IEEE 25 node scheme, which is composed of 13 load nodes and 9 generation nodes. Several operating conditions were modeled and compared with the results obtained in [25]. Simulations were also performed using the PSAT software and they are compared with results reported in bibliography [26, 27]. The errors are calculated considering as reference the bibliography and calculating them against the greater difference obtained by those from PSX. Table 1 show that for all cases the accuracy obtained is satisfactory with minor errors.

Table 1. Load margin comparison obtained by different simulation softwar

\begin{tabular}{ccccc}
\hline Contingencies & P (MW) & PSAT P (MW) & PSX P (MW) & Error (\%) \\
\hline BC- Base Case & 4635,81 & 4635,81 & 4638,66 & -0.004 \\
C1-Out of order Transf 3-24 & 4012,52 & 4012,52 & 4051,52 & -0.904 \\
C2- Out of order líne 2-4 & 4633,53 & 4633,25 & 4619,57 & 0.568 \\
\hline
\end{tabular}


The above table shows the accuracy values achieved with the previous methods. This comparison allowed to state that the implemented method showed an adequate precision. Makarov in [23] analyzes other contingencies that were also studied and compared during the research, being the value with a major difference the one obtained for condition $\mathrm{C} 1$.

\subsection{Contingency analysis considering PV and QV values different from zero}

The following load models show a comparison between maximum load values obtained considering continuous constant power and those obtained considering this variable with the voltage. The coefficients used were chosen based on data provided in [24] and considering a study carried out at a $110 / 34.5 \mathrm{kV}$ transformation station in Cuba [18].

Table 2 describes differences between loading margin and the maximum load point and the voltage collapse point. These differences can be above $250 \mathrm{MW}$, which represents for the study case a $5 \%$ of difference with respect to the base case approximately. The following table shows the difference in MW of considering the variable load with the voltage and considering it as constant power load. Comparisons are made considering the two points determined with respect to the values showed in Table 1

Table 2. Maximum power obtained in the contingencies analysis considering different types of load

\begin{tabular}{cccccccc}
\hline \multicolumn{2}{c}{ Coefficients } & \multicolumn{2}{c}{ Case Studies } & \multicolumn{2}{c}{ C2 } \\
PV & QV & Pmáx, P & $\begin{array}{c}\text { Instability, P } \\
\text { (MW) }\end{array}$ & $\begin{array}{c}\text { P Máx, P } \\
\text { (MW) }\end{array}$ & $\begin{array}{c}\text { Instability, P } \\
\text { (MW) }\end{array}$ & $\begin{array}{c}\text { P Máx, P } \\
\text { (MW) }\end{array}$ & $\begin{array}{c}\text { Instability, P } \\
(\text { MW) }\end{array}$ \\
\hline 1 & 1 & 4765,9 & 4866,5 & 4208,6 & 4419,6 & 4698,5 & 4849,8 \\
1 & 2 & 4834,9 & 4929,0 & 4347,0 & 4483,4 & 4797,4 & 4912,1 \\
{$[18]^{*}$} & {$[18]^{*}$} & 4870,7 & 4994,8 & 4366,7 & 4449,5 & 4866.4 & 4981,0 \\
{$[18]^{* *}$} & {$[18]^{* *}$} & 5006,9 & 5008,9 & 4543,3 & 4549,7 & 4951,6 & 4996,1 \\
$1,7[12]$ & $4,5[12]$ & 4990,2 & 5050,6 & 4594,9 & 4690,9 & 4953,8 & 5032,3 \\
\hline
\end{tabular}

* Values taken from [18] considering 35\% residential load, 35\% commercial load and 30\% industrial load in summer season

** Values taken from [18] but calculating an equivalent system for the same percentages using (4)

As is described in Table 3, the voltage-dependent load (active and reactive) cause critical values far removed from those obtained considering a constant load scenario. Also, consider the load as constant power guarantee optimist values however there can be values that do not take full advantage of the transmission capacities and therefore cause measurements to be taken in a hasty manner. In addition, voltage instability analysis gives remarkable information that can be obtained at the point of collapse because it is used to decide the accurate measure.

Another aspect that is important in these analyses of voltage instability is the valuable information that can Table 4 shows a comparison in each one of the previous cases of the eigenvalues at the maximum load point and in the critical point for voltage instability.

Table 3. Differences in MW between the maximum power values obtained considering a constant load and the values of the two points analyzed considering voltage-dependent load

\begin{tabular}{|c|c|c|c|c|c|c|c|}
\hline \multicolumn{8}{|c|}{ Study cases } \\
\hline \multicolumn{2}{|c|}{ Coeficcients } & \multicolumn{2}{|c|}{$\mathrm{BC}$} & \multicolumn{2}{|c|}{$\mathrm{C}-1$} & \multicolumn{2}{|r|}{$\mathrm{C}-2$} \\
\hline PV & QV & $\begin{array}{l}\text { P Máx, P } \\
\text { (MW) }\end{array}$ & $\begin{array}{l}\text { Instability, } P \\
\text { (MW) }\end{array}$ & $\begin{array}{l}\text { P Máx, P } \\
\text { (MW) }\end{array}$ & $\begin{array}{c}\text { Instability, } \mathrm{P} \\
\text { (MW) }\end{array}$ & $\begin{array}{l}\text { P Máx, P } \\
\text { (MW) }\end{array}$ & Instability, P (MW) \\
\hline 1 & 1 & 130,09 & 230,69 & 196,08 & 407,08 & 65,25 & 216,55 \\
\hline 1 & 2 & 199,09 & 293,19 & 334,48 & 470,88 & 164,15 & 278,85 \\
\hline$[18]^{*}$ & {$[18]^{*}$} & 251,13 & 375,23 & 354,18 & 436,98 & 246,83 & 361,43 \\
\hline$[18]^{* *}$ & {$[18]^{* *} *$} & 371,09 & 373,09 & 530,78 & 537,18 & 318,35 & 362,85 \\
\hline $1,7[12]$ & $4,5[12]$ & 354,31 & 414,79 & 582,38 & 678,38 & 320,55 & 390,05 \\
\hline
\end{tabular}

Table 4 shows eigenvalues in the two determined points. The bibliography state that in the voltage instability point, this value tends to zero, therefore its proximity to this value shows the accurate measure at this point. It is observed that for all values the eigenvalue at the maximum load point is higher than the obtained at the collapse point, which shows that they are two distant points. Although the literature states that the eigenvalue does not reflect the distance to the voltage collapse. In this case a modal analysis away from the voltage instability point can represent unimportant information. 
Table 4. Eigenvalues dominant in study cases

\begin{tabular}{|c|c|c|c|c|c|c|c|}
\hline \multicolumn{8}{|c|}{ Study Cases } \\
\hline \multicolumn{2}{|c|}{ Coefficients } & \multicolumn{2}{|c|}{$\mathrm{BC}$} & \multicolumn{2}{|c|}{$\mathrm{C}-1$} & \multicolumn{2}{|c|}{$\mathrm{C}-2$} \\
\hline PV & QV & P Máx, $\lambda$ & Instability, $\lambda$ & P Máx, $\lambda$ & Instability, $\lambda$ & P Máx, $\lambda$ & Instability, $\lambda$ \\
\hline 1 & 1 & 0,5572 & 0,00003 & 0,9229 & 0,000001 & 0,67248 & 0,000001 \\
\hline 1 & 2 & 0,51405 & 0,0002 & 0,28381 & 0,00001 & 0,55513 & 0,000002 \\
\hline$[18]^{*}$ & {$[18]^{*}$} & 0,55966 & 0,19934 & 0,71608 & 0,00003 & 0.50198 & 0,00001 \\
\hline$[18]^{* *}$ & {$[18]^{* *}$} & 0,1586 & 0,0003 & 0,01168 & 0,00002 & 0,2706 & 0,10608 \\
\hline $1,7[12]$ & $4,5[12]$ & 0,40597 & 0,0002 & 0,1881 & 0,01687 & 0,44241 & 0,00001 \\
\hline
\end{tabular}

* Values taken from [20] considering 35\% residential load, 35\% commercial load and 30\% industrial load in summer season.

** Values taken from [20] but calculating an equivalent for the same percentages by (4)

\subsection{Analysis of contingency $\mathrm{C}-1$ considering the load as a steady current case}

A more detailed analysis of one of the stability cases is discussed in this section. For this case a comparison is shown between the maximum load point and the voltage instability point considering that the load changes according to the coefficients determined for the Cuban substation cases showed in [18]. The case is simulated when the power transformer that links substations B103-B124 is out of service (contingency C-1). Table 5 shows results corresponding to the modal analysis, the participation factors of the nodes and series elements are shown for the points of maximum load and voltage instability.

Table 5. Participation factors in nodes and elements series from of the analyzed contingency

\begin{tabular}{|c|c|c|c|}
\hline \multicolumn{4}{|c|}{ Modal Analysis } \\
\hline \multicolumn{2}{|c|}{$\mathrm{P}$ maximum } & \multicolumn{2}{|c|}{ Instability } \\
\hline Critical nodes & Value & Critical nodes & Value \\
\hline B103 & 0,14858 & B103 & 0,15631 \\
\hline B106 & 0,09364 & B106 & 0,09417 \\
\hline B104 & 0,09184 & B104 & 0,08936 \\
\hline B101 & 0,09263 & B105 & 0,08791 \\
\hline B102 & 0,09109 & B101 & 0,08715 \\
\hline B105 & 0,09041 & B102 & 0,08514 \\
\hline Elements series & Value & Elements series & Value \\
\hline B111-B113 & 1 & B109-B125 & 1 \\
\hline B113-B112 & 0,954 & B125-B110 & 0,382 \\
\hline B112-B123 & 0,515 & --- & --- \\
\hline
\end{tabular}

The results of the simulations shown in Table 5 describe that can be obtained points with remarkable differences. Although the critical nodes coincide for both cases, their values and order are not the same. Nevertheless, this is not important because these points define a critical area that coincides for both cases. Something different occurs for the case of the predominant series elements, it is appreciated that in both cases there are different reason why the measures to take on the series elements refers for lines or transformers. The justification of the differences in the predominant series elements is based on the results shown in Table 6. For both cases the participation factors of generators are different, therefore those that reach the reactive power limit in both cases are different.

Table 6. Participation factors of the generators during the analyzed contingency case

\begin{tabular}{cccc}
\hline \multicolumn{4}{c}{ Modal analysis } \\
\multicolumn{2}{c}{ P maximum } & \multicolumn{2}{c}{ Instability } \\
Generators & Value & Generators & Value \\
\hline G1 & 0,1503 & G1 & 0,1464 \\
G2 & 0,00057 & G2 & 0,000124 \\
G3 & 0,00007 & G3 & 0,000127 \\
G5 & 0,01212 & G10 & 1 \\
G9 & 0,7068 & --- & -- \\
G10 & 1,000 & --- & --- \\
\hline
\end{tabular}

Table 6 shows the participation factors of the generators, an unequal value of zero implies that these generators deliver reactive power in the face of increasing demand and therefore have not reached their reactive limit. In the first case, six generators have different values of zero, while in the second case only four reach it. This cause a redistribution of the reactive power flow and justifies the existing difference in the participation factors of the series elements. Figure 4 shows the behavior of the critical node, B103, for the maximum load point and the voltage instability point. 


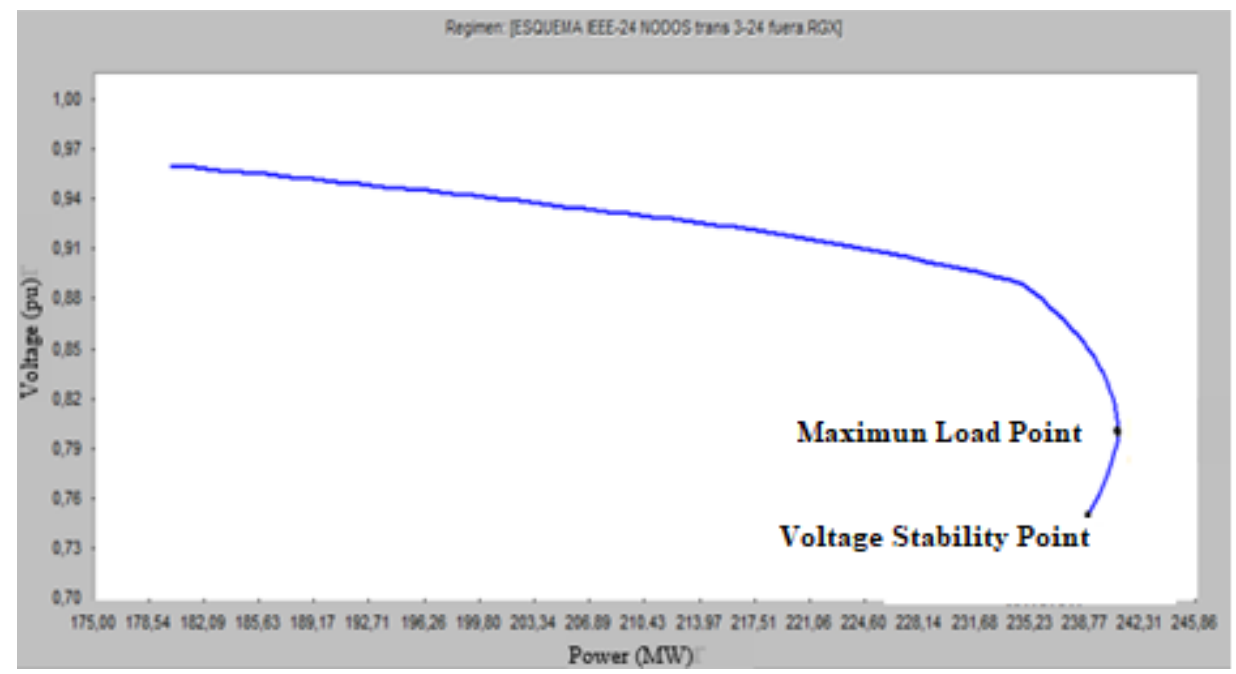

Figure 4. Maximum load and voltage instability point of node B103 for the analyzed case

\section{CONCLUSIONS}

Load modeling in the voltage stability studies has a decisive influence on the results obtained. Thus, depreciate it can cause that two different points appear during the analysis. An algorithm for load margin determination was implemented that includes the exponential characteristic of load dependence on voltage in power flow equations. Comparisons of software developed with commercial software demonstrate the accuracy achieved.

There are differences between the maximum load point and the voltage instability point, not only in the maximum power values delivered by the power system, but also in the predominant elements obtained from the modal analysis. These results are the ones that allow determining the main measures to move the operating point away from the voltage collapse point and therefore these differences in the results have repercussions in different measures. The load is not a constant power case as traditionally is considered during these studies, based on the results obtained in this work, more accurate approximations can be obtained if is determined the load dependence respect to the voltage and these values are included in the voltage stability studies.

\section{REFERENCES}

[1] O. G. Ibe, and A. I. Onyema, "Concepts of reactive power control and voltage stability methods in power system network," IOSR Journal of Computer Engineering, vol. 11(2), pp. 15-25, 2013.

[2] Y. A. Mobarak., "Voltage collapse prediction for Egyptian interconnected electrical grid EIEG, "International Journal on Electrical Engineering and Informatics, vol. 7(1), pp. 79-88, 2015.

[3] S. Gitanjali, et al., "Voltage Stability Prediction on Power Networks using Artificial Neural Networks," Indonesian Journal of Electrical Engineering and Computer Science (IJEECS), vol. 10(1), pp. 1-9, 2018.

[4] M. Khairuzzaman et al., "Optimal SVC allocation via symbiotic organisms search for voltage security improvement," TELKOMNIKA (Telecommunication, Computing, Electronics and Control), vol. 17 (3), pp. 1267-1274, 2019.

[5] R. Masood et al., "A statistical jacobian application for power system optimization of voltage stability," Indonesian Journal of Electrical Engineering and Computer Science (IJEECS), vol. 13(1), pp. 331-338, 2019.

[6] J. P. Sridhar and Prakash, R. "Multi-objective whale optimization based minimization of loss, maximization of voltage stability considering cost of DG for optimal sizing and placement of DG," International Journal of Electrical and Computer Engineering (IJECE), vol. 9(2), pp. 835-839, 2019.

[7] D. H. Aik Lee., "Voltage Stability Assessment Using Equivalent Nodal Analysis," IEEE transactions on Power Systems, vol. 31(1), pp. 454-463, 2016.

[8] S. Perez and L. Rodriguez, "A simplifield voltage stability index SVSI," International Journal of Electrical Power and Energy Systems, vol. 63(1), pp. 806-813, 2014.

[9] S. D. Sayed, et al., "A Review of Voltage Stability Assessment Technique with an Improved voltage Stability Indicator," International Journal of Emerging Electric Power Systems, vol. 16(2), pp. 107-115, 2015.

[10] L. F. Acevedo, G. Bothia-Vargas and J. E. Candelo., "Dynamic Voltage Stability Comparison of Thermal and Wind Power Generation with Different Static and Dynamic Load Models," International Journal of Electrical and Computer Engineering (IJECE), vol. 8(3), pp. 1401, 2018. 
[11] A. Mohamad, et al., "Voltage Instability Analysis for Electrical Power System Using Voltage Stabilty Margin and Modal Analysis," Indonesian Journal of Electrical Engineering and Computer Science (IJEECS), vol. 3(3), pp. 655-662. 2016.

[12] C. A. Canizares., "Voltage stability assessment: concepts, practices and tools," IEEE/PES power system stability subcommittee special publication SP101PSS, 2002.

[13] P. Singh., "On-line Assessment of Voltage Stability using Synchrophasor Technology," Indonesian Journal of Electrical Engineering and Computer Science (IJEECS), vol. 8(1), pp. 1-8. 2017.

[14] S. Gitanjali, et al., "Detection of Proximity to Voltage Collapse of Multi-Bus Power Network using Transmission Line Voltage Stability Indicator," Journal of Engineering and Applied Sciences, vol. 11(17), pp. 10689-10694. 2016.

[15] Z Garcia, et al., "Implementación de un estudio de estabilidad de la tensión al Paquete de Programas Psx. 2.87," Revista Ingeniería Energética, vol. 34(1), pp. 33-42, 2013.

[16] V. Sousa, H. H. Herrera, E. C. Quispe, P. R. Viego, and J. R. Gómez., "Harmonic Distortion Evaluation Generated by PWM Motor Drives in Electrical Industrial Systems," International Journal of Electrical and Computer Engineering (IJECE), vol. 7(6), pp. 3207-3216, 2017.

[17] V. Sousa, H. Hernández, E. C. Quispe, J. R. Gómez and P. R. Viego., "Analysis of harmonic distortion generated by PWM motor drives," In 2017 IEEE Workshop on Power Electronics and Power Quality Applications (PEPQA) pp. 1-6, 2017.

[18] Z. Garcia, et al., "Modelling of the load for stable state studies of voltage stability (in Spanish)," Revista Ingeniería Energética, vol. 34(2), pp. 129-136, 2013.

[19] L. Rodriguez, et al., "Parameter estimation of an exponential recovery load model using metaheuristic techniques (in Spanish)," Revista Scientia et Technica, vol. 18(3), pp. 453-462. 2013.

[20] S. Basu, et al., "Voltage Stability Margin (VSM ) and Maximum Loading Point (MLP) Of A Multi-Bus System Before and After Compensation," International Journal of Engineering Research and Development, vol. 5(7), pp. 30-35, 2013.

[21] Y. Zhichun, et al., "Analytical Method of Distributed Generation on Static Voltage Stability," TELKOMNIKA (Telecommunication, Computing, Electronics and Control), vol. 11(9), pp. 5018-5029, 2013.

[22] T. Van Cutsem and C. Vournas, "Voltaje Stability of Electric Power Systems," $3^{\text {rd }}$ ed., Springer Science \& Business Media, pp. 1-380, 2003.

[23] K. Jae-Kyeong, et al., "Fast and Reliable Estimation of Composite Load Model Parameters Using Analytical Similarity of Parameter Sensitivity," IEEE transactions on Power Systems, vol. 31(1), pp. 673-671, 2016.

[24] P. Kundur, "Power system stability and control," New York, The EPRI Power Systems Engineering Series 1st Ed, McGraw-Hill, pp. 306-311, 1994.

[25] Y. Makarov., "Expected Voltage Stability Margin," Consultado 6 de marzo de 2011, Disponible en: [Online] Available: http://ee.usyd.edu.au/ yuri/NAPS-98-EVSM.ps.

[26] J. Silva-Ortega., "Categorization and study of ieee9 Model toward transient stability analysis (in Spanish)" Inge CUC, vol. 8(1), pp. 173-190, 2012.

[27] Duran, Q. et al., "Recent trends of the most used metaheuristic techniques for distribution network reconfiguration," Journal of Engineering Science and Technology Review, vol. 10 (5), pp. 159-173, 2017.

\section{BIOGRAPHIES OF AUTHORS}

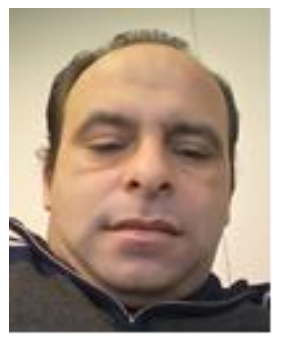

Zaid Garcia Sanchez. Electrical Engineer, Master of Science, Doctor of Technical Sciences, Full Professor, Center for Energy and Environment Studies (CEEMA), University of Cienfuegos E-mail: zgarcia@ucf.edu.cu, zaid@uclv.edu.cu.

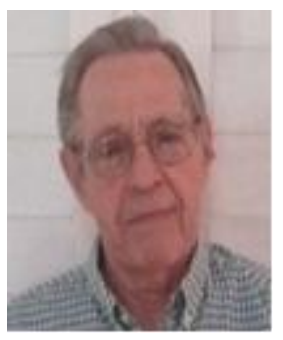

José Antonio González-Cueto Cruz. Electrical Engineer, Master of Science, Doctor of Technical Sciences, Senior Associate Professor, Center for Electroenergetic Studies (CEE), Central University "Marta Abreus" de las Villas.

E-mail: jcueto@uclv.edu.cu. 


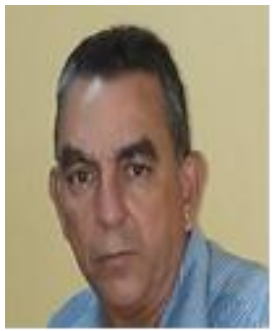

Gustavo Crespo Sánchez Electrical Engineer, Master of Science, Assistant Professor, Center for Energy Studies and Environment (CEEMA), University of Cienfuegos.

E-mail: gcsánchez@ucf.edu.cu.

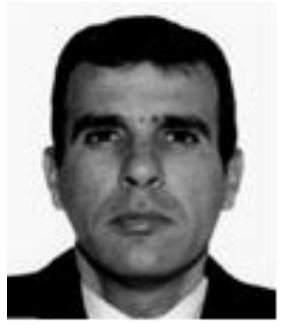

Hernan Hernández Herrera was born in Cienfuegos, Cuba on July 7, 1976. Received the B.S degree in Mechanical Engineering from the Universidad de Cienfuegos, Cuba in 2000. M. Sc. in applied mechanics from the Universidad de Cienfuegos, Cuba 2005. Received the Dr.C. (Ph.D.) degree from the Universidad de Cienfuegos, Cuba, in 2006. Currently is with Facultad de Ingenierias, Universidad Simon Bolivar, Colombia. His area of interest includes applied mechanics and energy efficiency.

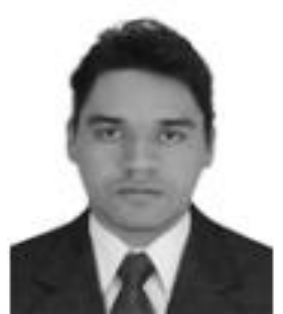

Jorge Iván Silva Ortega is Electrical and Electronic Engineer, Master in Electrical Engineering (2013) from the Universidad del Norte, Colombia. PhD student in Engineering at the Universidad Pontificia Bolivariana in Medellín, Colombia. Professor and researcher of the Universidad de la Costa, Colombia. He works to the energy department and joined to Research Group on Energy Optimization (GIOPEN) since 2011. His professional experience is related with electrical utilities sector. His research interests include: electrical power systems, electrical engineering education; planning, operation and control of power systems; and intelligent electrical networks. https:/orcid.org/0000-0002-7813-0142 